\title{
AUTOGENOUS SHRINKAGE OF COMPOSITES BASED ON PORTLAND CEMENT
}

\author{
Vendula Davidová, Pavel Reiterman* \\ Czech Technical University in Prague, Faculty of Civil Engineering, Thakurova 7, 16629 Prague, Czech \\ Republic \\ * corresponding author: pavel.reiterman@fsv.cvut.cz
}

\begin{abstract}
Autogenous shrinkage of cement based composites is important property influencing number of their engineering application. Its ultimate value is predominantly determined by mineralogical composition of cement and its particle size distribution. Present paper introduces experimental study focused on the evaluation of various cements of grade CEM I 42.5 produced in Czech Republic in terms of shrinkage under autogenous conditions. Selected cement type is currently the most frequently used cement. Conducted study confirmed essential differences in ultimate values of shrinkage, which is partially determined by its specific surface area. Accompanying tests of mechanical properties indicate the influence of particle size distribution, which controls initial phases of cement hydration.
\end{abstract}

KEYWORDS: Volume changes, shrinkage, cement mineralogy, mechanical properties.

\section{INTRODUCTION}

Portland cement based binder play an important role in structural engineering worldwide. It is caused by the efficiency of Portland cement and accessible raw materials for its production. Annual world production of Portland cement is approximately $3.8 \mathrm{Gt}$ and due to actual progress of economy worldwide is still rising. Traditional cement based concrete exhibits suitable values of compressive strength, however its low tensile performance is the reason of the risk of crack occurrence. There are many reasons of crack propagation; besides impacts of mechanical loadings, action of environment, thermal contraction, the shrinkage ranks to the most frequent reason of cracks propagation 1, 2, Figure 1. The presence of cracks significantly limits the service-life of concrete structures, because corrosion of steel reinforcement could reduce load capacity of the concrete element. In addition, expansive stresses, accompanying the steel corrosion, accelerate deterioration of the entire concrete. That is why, there is intensive attempt to mitigate cracks origin [1, 3].

Shrinkage of the concrete is complicated process, which consists of several aspects. However, it is suitable to distinguish shrinkage in early-age and during hardening. Especially, shrinkage at early-age went into general concern, because it presents period where the concrete is highly vulnerable to cracks propagation 4, 5. Commonly used technological provision is the partial replacement of Portland cement by supplementary cementitious materials (SCM) such as fly ash, granulated blast furnace slag, calcined clay, or silica fume [6, 7. However, kinetics of the hydration of the binder is crucial aspect as well. It is well documented on the application of silica fume, which could cause considerable shrinkage due to massive consumption of Portlandite; it is well illustrated on Figure 2

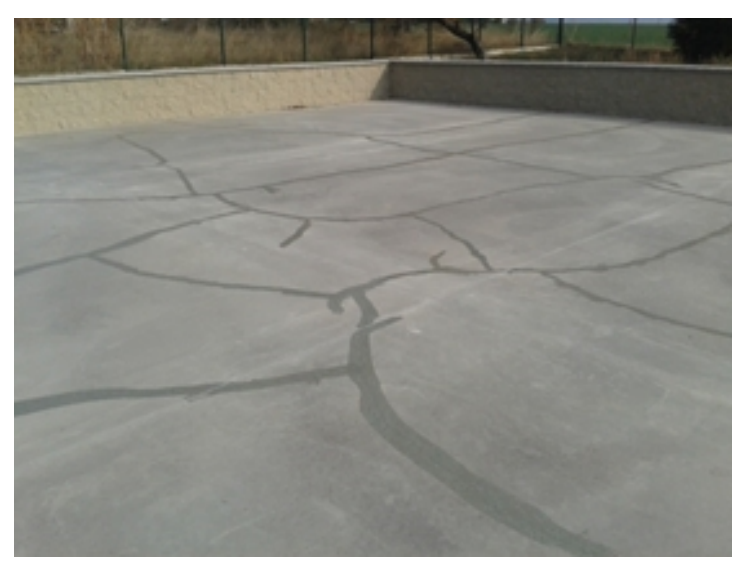

Figure 1. The example of cracks propagation due to shrinkage.

Besides factors of chemical shrinkage, there is number of elements affecting the shrinkage during hardening. The dominant one is the drying, thus loss of water content. The main problem of drying shrinkage is the non-linear distribution of originating stress, which culminates on the surface. Possible crack opening consequently accelerates moisture evaporation. Drying shrinkage has dominant importance during initial curing; poor discipline leads to massive rupture, well documented on Figure 1 Additionally, the shrinkage caused by carbonation could contribute, however its influence is minor in comparison with the drying shrinkage [1].

The measurement of concrete shrinkage is conducted by various experimental procedures. Autogenous shrinkage of hardening concrete was successfully determined using waved form, this arrangement allow contact less measurement 3. Special silicate composites are often investigated by so called 'absolute' method, which is based on the volumetric 


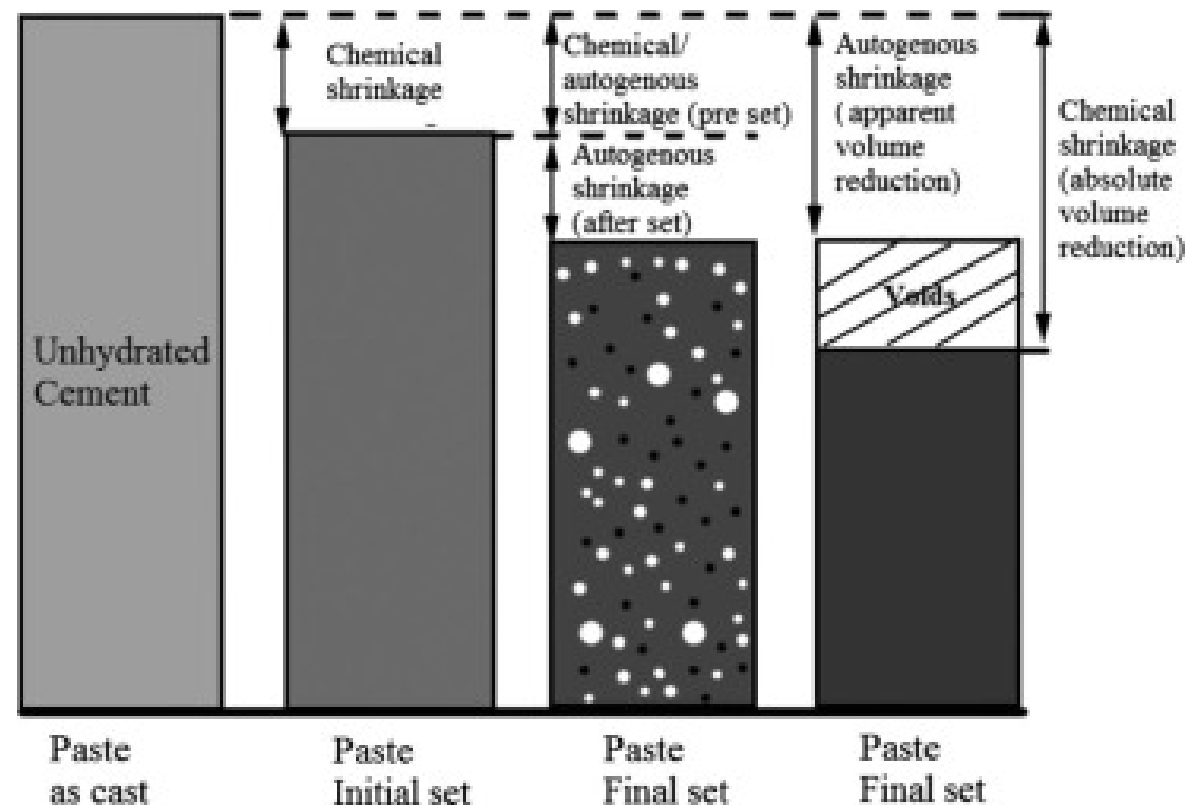

FiguRE 2. Illustration of concrete shrinkage [1].

measurement of sealed specimen immersed in a suitable liquid. This procedure is very complicated in its instrumentation, however offers the determination of entire chemical shrinkage. Free shrinkage in drains is the most frequently used procedure in technical praxis [3, 5. It is very simple and the test arrangement well corresponds with real conditions, because it allows to control the curing condition. Close to that is the measurement using traditional specimens with glued metal target for the fitting of the dilatometer. All these tests allow to obtain clear data, however their different arrangement needs precious interpretation of results obtained, because different aspects dominate in individual procedures. The drying shrinkage dominates during the measurement in bed, on the other hand samples with glued targets could be easily cured under specific conditions. The main aim of this paper is comparison of Portland cements of similar class cured under autogenous conditions to investigate their chemical shrinkage. Intentionally, cements with various finesses were selected for the study.

\section{EXPERIMENTAL PROGRAM}

Performed experimental program was focused on the determination of volume changes of Ordinary Portland Cement CEM I 42.5 produced by various producers. Chemical composition of the studied cements is introduced in Table 1. Selected cement type is currently the most frequently used cement type in Czech Republic. Volume changes were measured using prismatic specimens $20 \times 20 \times 100 \mathrm{~mm}$ made from mortar. Used mortar performed mix of standard sands and cement in weight ratio $3: 1$; water to cement ratio was set to 0.45 . The volume changes were monitored by using dial test indicator in specified time intervals. Similar methodology was used by Kotátková and Reiterman

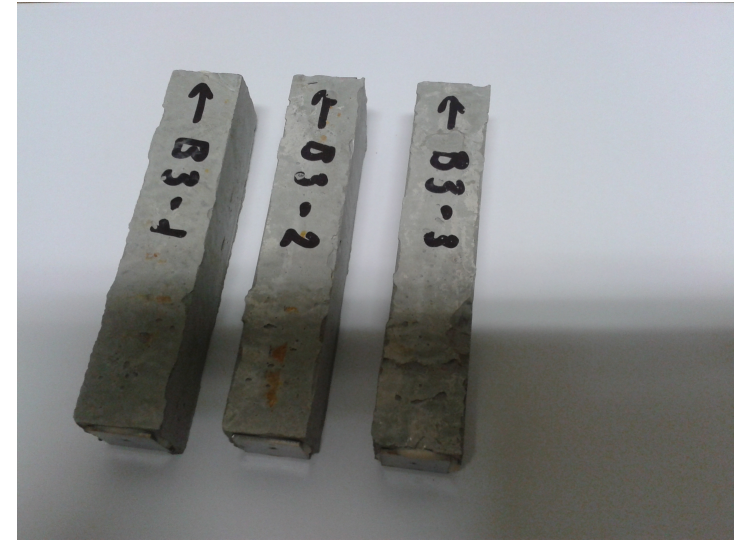

FiguRE 3. Used prismatic specimens.

[8. Used samples are shown in Figure 3. Concurrently was monitored weight of measured samples. Mechanical properties were determined in terms of BS EN 196-1 [9] on prismatic specimens $40 \times 40 \times 160 \mathrm{~mm}$ after 3 and 28 days of curing. The aim of performed work was to assess the autogenous volume changes, hence all samples were cured in water.

\section{Results AND Discussion}

Various cements of class $42.5 \mathrm{R}$ produced in Czech Republic were studied in terms of shrinkage and basic mechanical properties in time. Studied materials exhibited different chemical composition and specific surface. It was confirmed, as expected, that basic properties of cement have essential influence on the studied properties having a high engineering importance. Results of the measurement of the shrinkage are shown in Figure 4 it is necessary to note, that all samples were cured under wet condition to quantify the influence of chemical shrinkage. However, applied 


\begin{tabular}{ccccccccccc}
\hline & $\begin{array}{c}\mathrm{CaO} \\
{[\%]}\end{array}$ & $\begin{array}{c}\mathrm{SiO}_{2} \\
{[\%]}\end{array}$ & $\begin{array}{c}\mathrm{Al}_{2} \mathrm{O}_{3} \\
{[\%]}\end{array}$ & $\begin{array}{c}\mathrm{Fe}_{2} \mathrm{O}_{3} \\
{[\%]}\end{array}$ & $\begin{array}{c}\mathrm{MgO} \\
{[\%]}\end{array}$ & $\begin{array}{c}\mathrm{SO}_{3} \\
{[\%]}\end{array}$ & $\begin{array}{c}\mathrm{K}_{2} \mathrm{O} \\
{[\%]}\end{array}$ & $\begin{array}{c}\mathrm{Na}_{2} \mathrm{O} \\
{[\%]}\end{array}$ & $\begin{array}{c}\mathrm{LOI} \\
{[\%]}\end{array}$ & $\begin{array}{c}\text { Blaine } \\
{\left[\mathrm{m}^{2} / \mathrm{kg}\right]}\end{array}$ \\
\hline $\mathrm{A}$ & 63.70 & 19.60 & 4.80 & 3.20 & 1.40 & 3.10 & 0.76 & 0.19 & 3.50 & 414 \\
$\mathrm{~B}$ & 63.80 & 20.60 & 4.80 & 3.40 & 1.40 & 3.20 & 0.74 & 0.20 & 1.40 & 311 \\
$\mathrm{C}$ & 61.20 & 21.70 & 5.72 & 3.22 & 2.58 & 2.94 & 0.80 & 0.30 & 1.29 & 351 \\
\hline
\end{tabular}

TABle 1. Properties of studied cements.

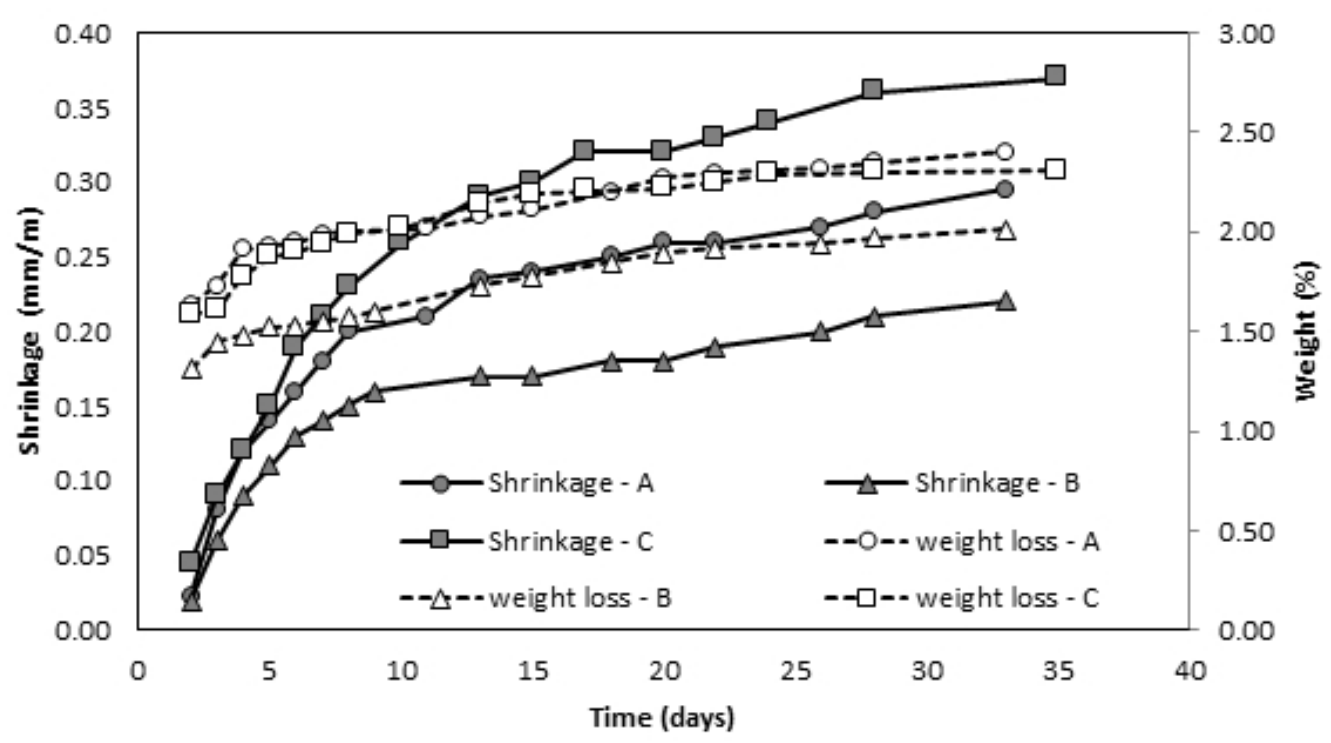

Figure 4. Results of shrinkage measurement.

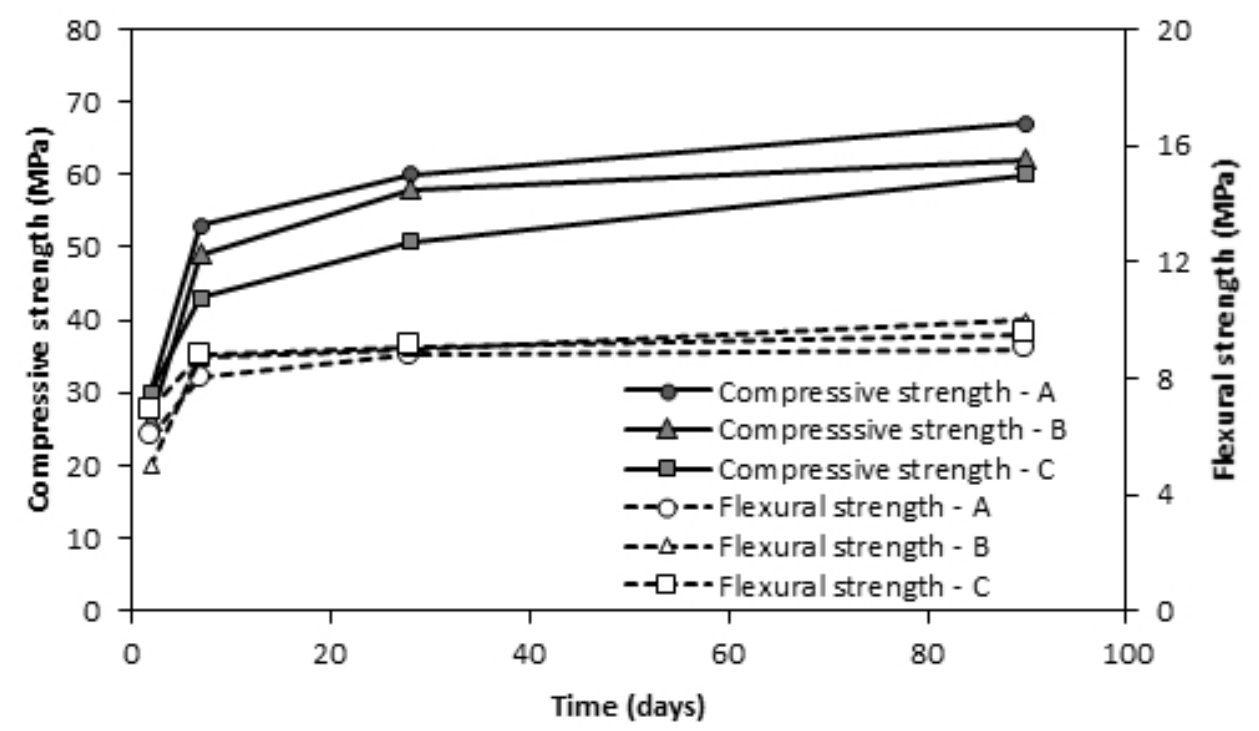

Figure 5. Results of shrinkage measurement. 
condition caused slow increase of the volume for all studied materials. It is caused by the fixation of water and air in capillary system of hardened mortar.

The lowest volume changes exhibited cement with the lowest value of specific surface area, it is well visible on Figure 4, that this cement has also retarded initial kinetics. The measurement of weight changes well corresponds with the determination of volume changes. On the other hand, cements with various surface area reached inverse trend in terms of volume changes. It could be caused by the different particle size distribution, which was not, unfortunately, studied in the paper. However, number of practical experiences accent unsuitability the surface area determination for special problems such as volume changes and cement calorimetry. There are evident lacks on the standard level in Czech Republic.

Mechanical properties of studied cements are presented in Figure 5 It can be concluded, that studied cements exhibited similar mechanical performance, what can be expected for cements of similar class. However, detailed view on the results can offer interesting findings; evolution of mechanical properties of cement " $\mathrm{C}$ " is rapidly faster in early ages in comparison with the others. It is well visible on the evolution of flexural strength. Paradoxical, cement designated "C" showed the highest volume changes, but lowest mechanical performance in terms of compressive strength.

\section{Conclusion}

Performed experimental program was aimed at the comparison of various cements of class $42.5 \mathrm{R}$ produced in Czech Republic, which all meet the requirement of EN 197-1 [10]. Studied material exhibited similar mechanical performance, however differences in chemical composition and basic physical properties caused significant differences in terms of volume changes. The program showed, that standard requirements, especially surface area, are not reliable criterion for prediction of volume changes. Present topic needs following research with focus on the hydration kinetics.

\section{ACKNOWLEDGEMENTS}

This study was supported by the research project FV30062 "Possibilities of utilization of coal-ash from power stations stored at stock piles".

\section{REFERENCES}

[1] L. Wu, N. Farzadnia, C. Shi, et al. Autogenous shrinkage of high performance concrete: A review. Construction and Building Materials 149:62-75, 2017. DOI:10.1016/j.conbuildmat.2017.05.064.

[2] S. A. Al-Saleh. Comparison of theoretical and experimental shrinkage in concrete. Construction and Building Materials 72:326-332, 2014. DOI:10.1016/j.conbuildmat.2014.06.050

[3] K. Kolar, J. Litos, Z. Bazantova, P. Reiterman. Comparison of two methods for determination of volume changes of cement based composites. In P.Padevět, P. Bittnar (eds.), EAN 2015 - 53rd Conference on Experimental Stress Analysis, pp. 173-176. 2015.

[4] A. Zemanova, R. Sovjak, J. Litos. Restrained shrinkage test of high performance concrete ring specimen. Advanced Materials Research 982:38-43, 2014. DOI:10.4028/www.scientific.net/AMR.982.38.

[5] B. Kucharczyková, D. Kocáb, I. Rozsypalová, et al. Measurement and evaluation proposal of early age shrinkage of cement composites using shrinkage-cone. IOP Conference Series: Materials Science and Engineering 379(012038), 2018. DOI:10.1088/1757-899x/379/1/012038

[6] U. Haider, Z. Bittnar, L. Kopecky, et al. Determining the role of individual fly ash particles in influencing the variation in the overall physical, morphological, and chemical properties of fly ash. Acta Polytechnica 56:265, 2016. DOI:10.14311/AP.2016.56.0265.

[7] I. Nováková, L. Bodnárová, T. Stavař, R. Hela. Evaluation of disruption of concrete caused by exposure to high temperatures by initial surface absorption test. ARPN Journal of Engineering and Applied Sciences 10:6299-6304, 2015.

[8] J. Kotátková, P. Reiterman. Preliminary study on design of biological shielding concrete - Selection of binder. In Special Concrete and Composites 2016, vol. 722 of Key Engineering Materials, pp. 173-177. Trans Tech Publications, 2017. DOI:10.4028/www.scientific.net/KEM.722.173

[9] BS EN 196-1:2016 - Methods of testing cement. Determination of strength. Standard, British Standards Document, 2016. DOI:10.3403/30291447U.

[10] BS EN 197-1:2011 - Cement. Composition, specifications and conformity criteria for common cements. Standard, British Standards Document, 2011. 